NASA Technical Memorandum 107267

AIAA-96-2943

\title{
Experimental Evaluation of the Ignition Process of Carbon Monoxide and Oxygen in a Rocket Engine
}

Diane L. Linne

Lewis Research Center

Cleveland, Ohio

Prepared for the

32nd Joint Propulsion Conference

cosponsored by AIAA, ASME, SAE, and ASEE

Lake Buena Vista, Florida, July 1-3, 1996

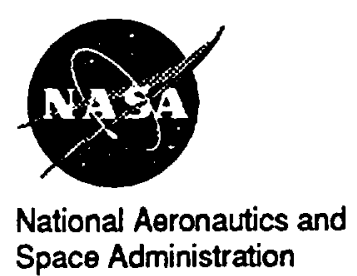




\title{
EXPERIMENTAL EVALUATION OF THE IGNITION PROCESS OF CARBON MONOXIDE AND OXYGEN IN A ROCKET ENGINE
}

\author{
Diane L. Linne \\ National Aeronautics and Space Administration \\ Lewis Research Center \\ Cleveland, Ohio 44135
}

\begin{abstract}
Carbon monoxide and oxygen ignition boundaries were determined in a spark torch igniter as a function of propellant inlet temperatures. The oxygen temperature was varied from ambient to $-258^{\circ} \mathrm{F}$, and the carbon monoxide temperature was varied from ambient to $-241^{\circ} \mathrm{F}$. With the oxygen and carbon monoxide at $-253^{\circ} \mathrm{F}$ and $-219^{\circ} \mathrm{F}$, respectively, they successfully ignited between mixture ratios of 2.42 and 3.10. Analysis of the results indicated that the lower ignition boundary was more sensitive to oxygen temperature than to carbon monoxide temperature. Another series of tests was performed in a small simulated rocket engine with oxygen at $-197^{\circ} \mathrm{F}$ and carbon monoxide at $-193{ }^{\circ} \mathrm{F}$. An oxygen/hydrogen flame was used to initiate combustion of the oxygen and carbon monoxide. Tests performed at the optimum operating mixture ratio of 0.55 obtained steadystate combustion in every test.
\end{abstract}

\section{Introduction}

Currently, proposed planetary exploration missions must be small, low-cost, and have a short development time. Relatively high-risk technologies are being accepted if they are required to meet these guidelines. For a Mars sample return mission, one of those higher-risk technologies is the use of return propellants produced from indigenous materials (ref. 1).

Copyright 0 by the American Institute of Aeronautics and Astronautics, Inc. No copyright is asserted in the United States under Title 17, U.S. Code. The U.S. Government has a royalty-free license to exercise all rights under the copyright claimed berein for Governmental Purposes. All other rights are reserved by the copyright owner.
In order to reduce the complexity of a sample return mission, the currently favored scenario consists of a direct landing on Mars, and a launch to direct return to Earth. This scenario, while having high propulsion requirements, eliminates the need for an autonomous rendezvous in low Mars orbit to transfer the sample to an orbiting Earth return vehicle. To reduce the propulsion requirement of this scenario, the use of in situ propellants is being investigated. The atmosphere of Mars consists of 96 percent carbon dioxide, which can be processed into oxygen, and either carbon monoxide or methane for the fuel. $\mathrm{CO}$ has a relatively low specific impulse, but has the advantage of being comprised entirely of indigenous materials. Methane, while having better performance, requires the transport from Earth of some liquid hydrogen. With in situ production, the return propellants could be replaced by a lightweight production plant which would manufacture the return propellants from the Mars atmosphere while the sample is being collected. Mission analyses indicate that the mass required to be landed on the martian surface may be reduced 40 to 60 percent as compared to a mission where all propellants are brought from Earth (refs. 2-4).

Experimental and theoretical research has been performed with the carbon monoxide and oxygen propellant combination at the subscale level to prepare the technology for use in a sample return mission. This research included ignition characterization, combustion performance, and heat transfer characterization (refs. 5-7). However, most of the experimental work was performed with gaseous propellants at room temperature.

Previous ignition characterization experiments determined the boundaries of 
ignition as a function of oxygen to fuel mixture ratio and oxygen inlet temperature. In the experiments, the carbon monoxide was injected as a gas, and the oxygen was chilled to nearliquid temperatures. These conditions approximated those in a pump fed engine, where one propellant is used to run the turbopumps and therefore enters the engine warm. For a pressure fed engine where the propellants are stored cryogenically, they will most likely both enter the engine cold. Therefore, there was a need for experimental evaluation of the ignition process with both the carbon monoxide and oxygen at near-liquid temperatures.

The results of the previous ignition experiments indicated that as the oxygen temperature decreased, the minimum mixture ratio for ignition increased to well above stoichiometric (oxygen-to-fuel ratio of 0.571 ). These results raised the question of whether an engine burning oxygen and carbon monoxide must operate within the same mixture ratio range as the igniter. Such a high engine mixture ratio would significantly reduce performance and would greatly affect mission planning. Therefore, there was a need for a demonstration of combustion of cold oxygen and carbon monoxide at optimum mixture ratio to validate this propellant combination for a Mars mission. Theoretical prediction of specific impulse indicates that a mixture ratio of 0.55 provides optimum performance. For this demonstration, ignition devices other than an oxygen/carbon monoxide spark torch were considered. These included an oxygen/hydrogen spark torch igniter, hypergolics, and laser ignition, which had been previously demonstrated with warm oxygen and carbon monoxide (ref. 8). The $\mathrm{O}_{2} / \mathrm{H}_{2}$ igniter was used in these tests. Although the $\mathrm{O}_{2} / \mathrm{H}_{2}$ igniter and hypergolics would require some propellants brought from Earth, the quantity required for an igniter would be very small.

\section{Test Apparatus and Procedure}

The experimental tests were performed in cell 21 of the Rocket Laboratory at the
NASA Lewis Research Center. A general description of this facility is given in references 5 and 9. Components of the facility, hardware, and procedure that were unique to these experiments are described in this section.

\section{Test Facility}

For this program, gaseous oxygen, hydrogen, and carbon monoxide were used, as well as a liquid nitrogen heat exchanger (fig. 1). Two oxygen lines were used. The primary line passed through the liquid nitrogen heat exchanger to chill the oxygen to near-liquid temperatures. The secondary oxygen line bypassed the heat exchanger and connected with the primary line downstream. By varying the amount of oxygen flow in the two lines, the oxygen temperature at the igniter inlet could be controlled. Similarly, two lines were used in the carbon monoxide system, with one passing through the heat exchanger and one bypassing it before the two gas streams mixed together. In addition, a gaseous hydrogen line tied in to the combined carbon monoxide line just upstream of the igniter. The hydrogen was included to provide the necessary catalyst agent to initiate ignition (ref. 5).

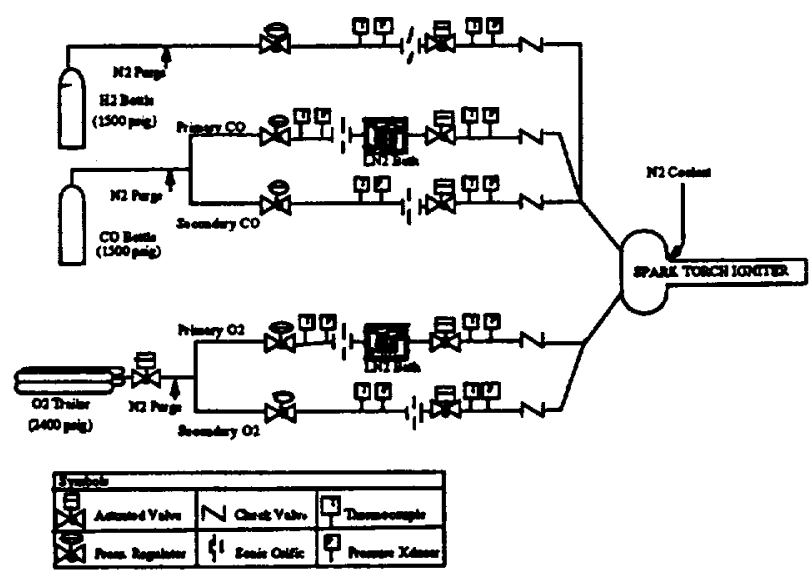

Figure 1. Flow schematic of test cell 21 of the Rocket Laboratory, NASA Lewis Research Center.

For all tests, the total flow rate of the oxygen and carbon monoxide was held constant at $6.35 \mathrm{gm} / \mathrm{sec}(0.014 \mathrm{lbm} / \mathrm{sec})$. This flow provided for a nominal steady-state 
combustion pressure of $690 \mathrm{kPa}$ (100 psia). The hydrogen flow rate added to the carbon monoxide flow was held constant at the minimum controlled capability of the system $(0.0059 \mathrm{gm} / \mathrm{sec} ; 0.000013 \mathrm{lbm} / \mathrm{sec})$. This amount of hydrogen proved sufficient in previous experiments to catalyze the ignition.

\section{Test Hardware}

The hardware was a spark torch igniter with a coolant sleeve (fig. 2). The oxygen and carbon monoxide were injected in opposing jets into a small chamber $1.9 \mathrm{~cm}(0.75$ inch) diameter by $1.3 \mathrm{~cm}(0.50$ inches) deep. They were lit by a standard spark plug. After ignition, the combustion gases passed into a $0.36 \mathrm{~cm}$ diameter by $8.9 \mathrm{~cm}$ long tube $(0.14$ by 3.5 inch), and then exited to atmosphere. To cool this exit tube, gaseous nitrogen flowed through a surrounding concentric tube.

This igniter hardware is the size and type that has been used to ignite many experimental engines at NASA Lewis with thrust levels ranging from $110 \mathrm{~N}(25 \mathrm{lbf})$ to $70,000 \mathrm{~N}(16,000 \mathrm{lbf})$. It was therefore considered to be of appropriate size for a Mars sample return engine of approximately $2200 \mathrm{~N}$ (500 lbf) thrust.

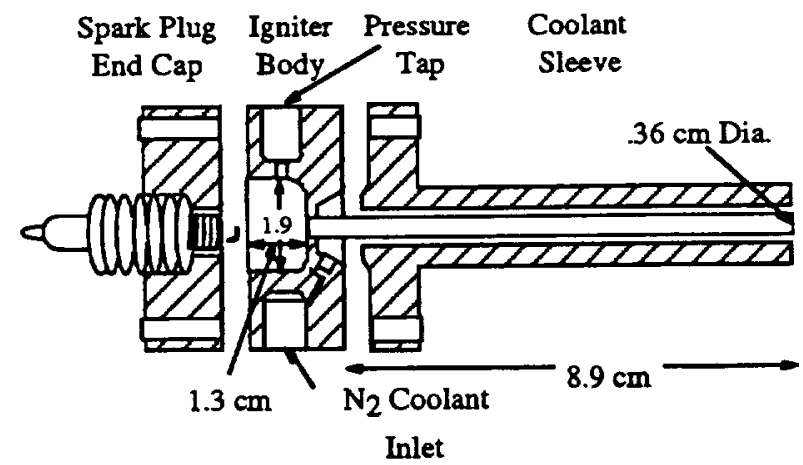

Note: $O_{2}$ and CO opposing inlets (not shown) at $45^{\circ}$ to $\mathrm{N}_{2}$ coolant and pressure tap.

Figure 2. Spark torch igniter hardware.

\section{Test Procedure}

To insure a uniform run profile throughout the duration of the test program, each firing of the igniter was sequenced by a programmable line controller (PLC). After the desired gas flow rates were set by adjusting the pressures upstream of the sonic orifices, the PLC was initiated and the flow of fuel and oxygen, as well as the ignition spark, were automatically sequenced in a pre-programmed pattern. The PLC used for these experiments had an accuracy of \pm 0.020 seconds.

Because the boiling point of nitrogen is slightly lower than the boiling point of oxygen, and similar to that of carbon monoxide, the oxygen and carbon monoxide in the heat exchanger coils condensed between runs. To insure a steady-state, one-phase flow of propellants, each test was started with a 10 second pre-flow of oxygen. The hydrogen was also started at this time to allow the very small flow rate time to reach steady-state. To limit the amount of carbon monoxide used and vented to atmosphere, the carbon monoxide was turned on 8 seconds after the oxygen. Ten seconds after the oxygen pre-flow started the test (and 2 seconds after the carbon monoxide started), the spark was turned on for 1.2 seconds. The hydrogen was shut down 0.5 seconds after spark initiation. This allowed the hydrogen to catalyze the ignition process, but was shut down soon enough to verify that the dry carbon monoxide and oxygen reaction was self-sustaining after ignition. This sequencing is depicted in figure 3 .

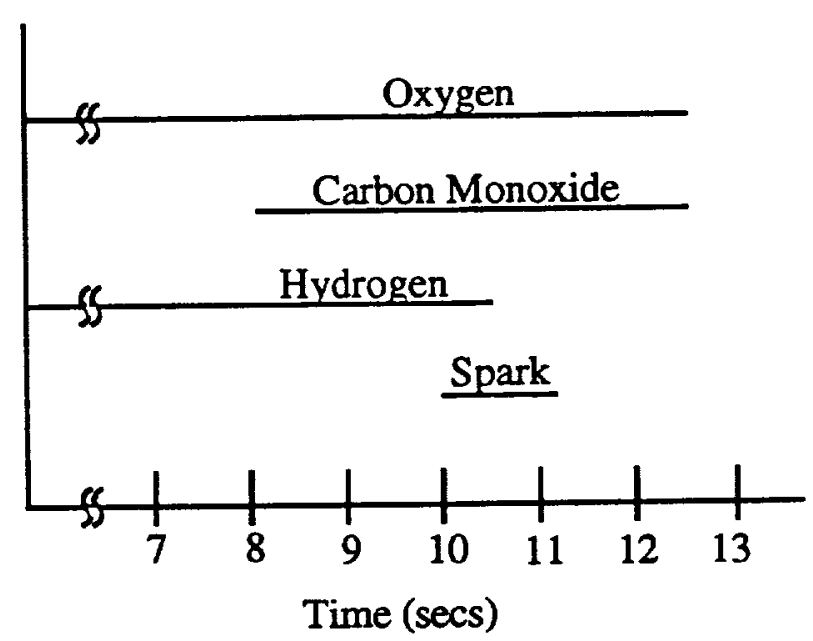

Figure 3. Automatic timing sequence of propellants and spark. 
For the tests where some cold carbon monoxide was used, the primary $\mathrm{CO}$ flow valve was opened manually for a few seconds before the test sequencing was started. This allowed the condensed CO to flow out of the heat exchanger coils and also helped to keep the lines chilled.

\section{Design of Experimental Methodology}

There were two controlled variables, or factors, in the experiment: inlet temperature of oxygen, and inlet temperature of carbon monoxide. By varying both of these temperatures independently, the result was a complete map of the ignition characteristics for all inlet conditions and therefore for any engine cycle. For both the oxygen and the carbon monoxide, three inlet temperatures were included in the test matrix. These temperatures were called 'low', 'mid', and 'high'. The 'low' temperature was obtained by flowing all of the gas through the liquid nitrogen heat exchanger. The 'mid' temperature was obtained by flowing half of the gas through the heat exchanger and keeping half of the gas at ambient temperature. The 'high' temperature was obtained by keeping all of the gas at ambient temperature. The test matrix consisted of a complete combination of the two controlled factors (i.e. low-low, low-mid, low-high, midlow, etc).

The response variable was the mixture ratio at which ignition occurred. A high-low search scheme was utilized to determine the response at each combination of inlet temperatures. First, a mixture ratio was tested where ignition was expected to occur. Then, a mixture ratio was tested where ignition was not expected to occur. A third mixture ratio halfway between the first two was then tested. Based on the results of this test (i.e. ignition or no ignition), a fourth test was performed at a mixture ratio halfway between the closest ignition and no ignition conditions. Testing continued in this manner until the ignition boundary was determined to an acceptable accuracy. This process was performed twice at some of the inlet conditions to increase statistical confidence in the results.
During the high-low searching at each test condition, it was not possible to hold the inlet temperatures of oxygen and carbon monoxide absolutely constant. This variation in temperature was also not consistent for each point in the test matrix. For the oxygen, the 'low' temperature was fairly consistent, and ranged between $-245^{\circ} \mathrm{F}$ and $-260^{\circ} \mathrm{F}$. At the typical pre-spark chamber pressure of $517 \mathrm{kPa}$ (75 psia), the saturation temperature of oxygen is $-263^{\circ} \mathrm{F}$. Therefore, although the oxygen was in a vapor state, it was very near liquid conditions. The 'high' oxygen temperature depended on the ambient conditions, and ranged from $41{ }^{\circ} \mathrm{F}$ to $75^{\circ} \mathrm{F}$. The 'mid' temperature was the most difficult to control, and final temperatures ranged from $-1^{\circ} \mathrm{F}$ to $-173^{\circ} \mathrm{F}$.

For the carbon monoxide, the 'low' temperature was not as consistent as for the oxygen, most likely due to the shorter pre-flow times. It ranged from $-207^{\circ} \mathrm{F}$ to $-241^{\circ} \mathrm{F}$. At a chamber pressure of $517 \mathrm{kPa}$ (75 psia), the saturation temperature of carbon monoxide is approximately $-282^{\circ} \mathrm{F}$. Therefore, the coldest carbon monoxide temperatures obtained were still $40^{\circ} \mathrm{F}$ warmer than liquid conditions. The 'high' carbon monoxide temperature was similar to that of oxygen, ranging from $37^{\circ} \mathrm{F}$ to $74^{\circ} \mathrm{F}$. The 'mid' temperature was again the most inconsistent, and ranged from $-8^{\circ} \mathrm{F}$ to $-163^{\circ} \mathrm{F}$.

\section{Results and Discussion}

As in previous experiments (ref. 5), it was apparent that there was not a sharp jump from no-ignition to ignition. Instead, there was a gradual transition as mixture ratio was increased. Five stages of the response variable were defined as below.

No Ignition. No reaction was identified by means of sound, visible plume, or pressure rise in the ignition chamber.

Weak Reaction. This category was characterized by a small, unsteady, pressure rise, some combustion noise, and a faint, sporadic visible plume. 
Half Ignition. Plume was visible during test. Significant, continual pressure rise. This category was characterized by reactions only during spark activity. This indicated that the ignition process was initiated but was not able to sustain without an external energy source.

Early Shutdown. Plume was visible during test. Pressure rise approached steady-state. This category was characterized by reactions that continued after the spark shutdown, but ended before the oxygen and fuel flows were shut off.

Full Ignition. Successful ignition sustained until the oxygen and fuel flows were stopped. This category was characterized by a strong, steady visible plume, and the attainment of a steadystate pressure.

\section{Determination of Ignition Boundary}

The mixture ratios reported as the ignition boundary are the mixture ratios above

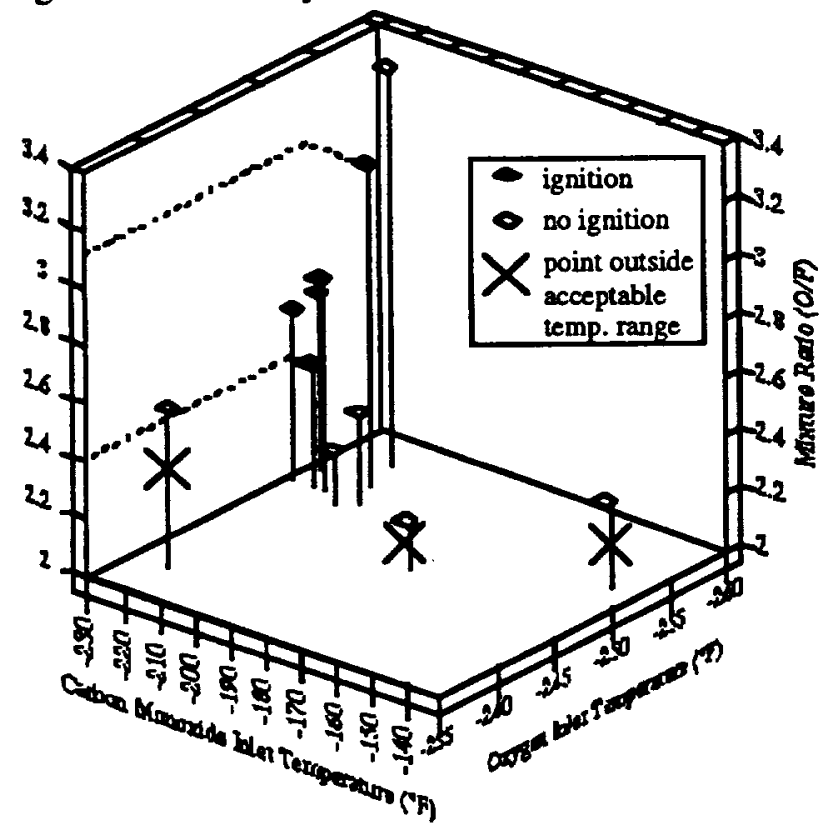

Figure 4. Experimental results of ignition tests with oxygen $\left(-253^{\circ} \mathrm{F}\right)$ and carbon monoxide $\left(-219^{\circ} \mathrm{F}\right)$. which full ignition always occurred (at the lower ignition boundary), or below which full ignition always occurred (at the upper ignition boundary). Figure 4 is an example of the data that was obtained for each combination of the propellants inlet temperatures. The figure shows the results of tests performed with both the oxygen and the carbon monoxide at the 'low' temperature condition. Only test points where both the oxygen and carbon monoxide were within $10^{\circ} \mathrm{F}$ of a mean value were considered in the determination of ignition boundary. Therefore, the two test points at carbon monoxide temperatures of $-138^{\circ} \mathrm{F}$ and $-178^{\circ} \mathrm{F}$ were excluded. Also excluded was the test point at an oxygen temperature of $-139^{\circ} \mathrm{F}$, as this was more than 10 degrees warmer than the mean oxygen temperature of $-251^{\circ} \mathrm{F}$.

From the remaining points within 10 degrees of the mean temperatures of $-253^{\circ} \mathrm{F}$ (oxygen) and $-219^{\circ} \mathrm{F}$ (carbon monoxide), the last test point at which ignition occurred was designated as the boundary. From this test series, the lower ignition boundary was determined to be at a mixture ratio of 2.423 , and the upper boundary at a mixture ratio of 3.104. Ignition boundaries from each test series were determined in a similar manner. Table I lists the results of the tests.

A statistical computer program was used to perform a multiple regression on the results (ref. 10). This analysis produced a response surface model for the lower and upper boundaries. The terms considered for each model were oxygen temperature, oxygen temperature squared, carbon monoxide temperature, carbon monoxide temperature squared, and oxygen temperature times carbon monoxide temperature. Figure 5a shows the experimental test results, and figure $5 \mathrm{~b}$ shows the model developed for the lower mixture ratio boundary. A natural log transformation of the response (mixture ratio) was used in the analysis to develop a more accurate model of the experimental data. The model for the lower boundary is:

$\ln \left(\mathrm{O} / \mathrm{F}_{\text {lower }}\right)=-0.414029-0.0036789 * \mathrm{~T}_{\mathrm{ox}}$ $+0.00062535 * \mathrm{~T}_{\mathrm{co}}+0.0000683 * \mathrm{~T}_{\mathrm{ox}} * \mathrm{~T}_{\mathrm{co}}$ 
Table I. Results of Experimental Ignition Tests.

\begin{tabular}{|r|r|r|r|r|r||}
\hline \multicolumn{3}{|c|}{ Lower Boundary } & \multicolumn{3}{c|}{ Upper Boundary } \\
\hline $\begin{array}{r}\text { Ox. } \\
\left({ }^{\circ} \mathrm{F}\right)\end{array}$ & $\begin{array}{c}\mathrm{CO} \\
\left({ }^{\circ} \mathrm{F}\right)\end{array}$ & O/F & $\begin{array}{l}\text { Ox. } \\
\left({ }^{\circ} \mathrm{F}\right)\end{array}$ & $\begin{array}{c}\text { CO } \\
\left({ }^{\circ} \mathrm{F}\right)\end{array}$ & \multicolumn{1}{c|}{ O/F } \\
\hline-253 & -219 & 2.423 & -253 & -219 & 3.104 \\
\hline-251 & -138 & 2.038 & -260 & 2.8 & 2.774 \\
\hline-253 & -51 & 1.363 & -257 & 61 & 2.347 \\
\hline-258 & -8 & 2.084 & -93 & -163 & 2.579 \\
\hline-247 & 44 & 1.291 & -51 & -162 & 2.792 \\
\hline-173 & 63 & 1.289 & -173 & 63 & 1.985 \\
\hline-50 & 37 & 0.750 & -50 & 37 & 1.948 \\
\hline-24 & -207 & 0.729 & 51 & -214 & 1.700 \\
\hline-9 & -241 & 0.672 & 75 & 74 & 1.444 \\
\hline-1 & -52 & 0.639 & & & \\
\hline 41 & -55 & 0.518 & & & \\
\hline 75 & 74 & 0.500 & & & \\
\hline
\end{tabular}

The analysis determined that both the oxygen and carbon monoxide temperature, as well as the interaction between the two, affected the boundary. However, it is clear from the equation and the figure that the boundary was most affected by changes in oxygen temperature.

Figure 6 shows the experimental test results and analytical model for the upper mixture ratio boundary. The model for the upper boundary is:

$\mathrm{O} / \mathrm{F}_{\text {upper }}=2.049205-0.00285583 * \mathrm{~T}_{\mathrm{ox}}$ $0.00459746 * \mathrm{~T}_{\text {co }}-0.00002379 * \mathrm{~T}_{\mathrm{co}^{2}}+$ $0.00000854 * \mathrm{~T}_{\text {ox }} * \mathrm{~T}_{\mathrm{co}}$

In this case, the model also includes a term for carbon monoxide temperature squared. It can be seen from the equation and the figure that the upper ignition boundary was equally affected by oxygen temperature and carbon monoxide temperature, and was also highly

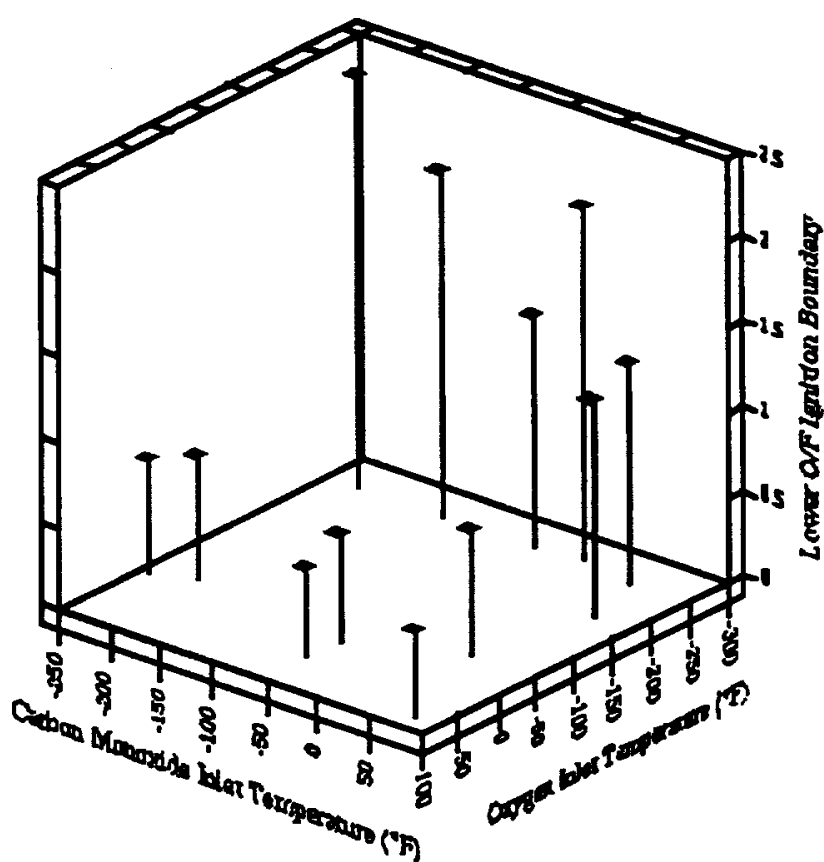

(a). - Experimental results.

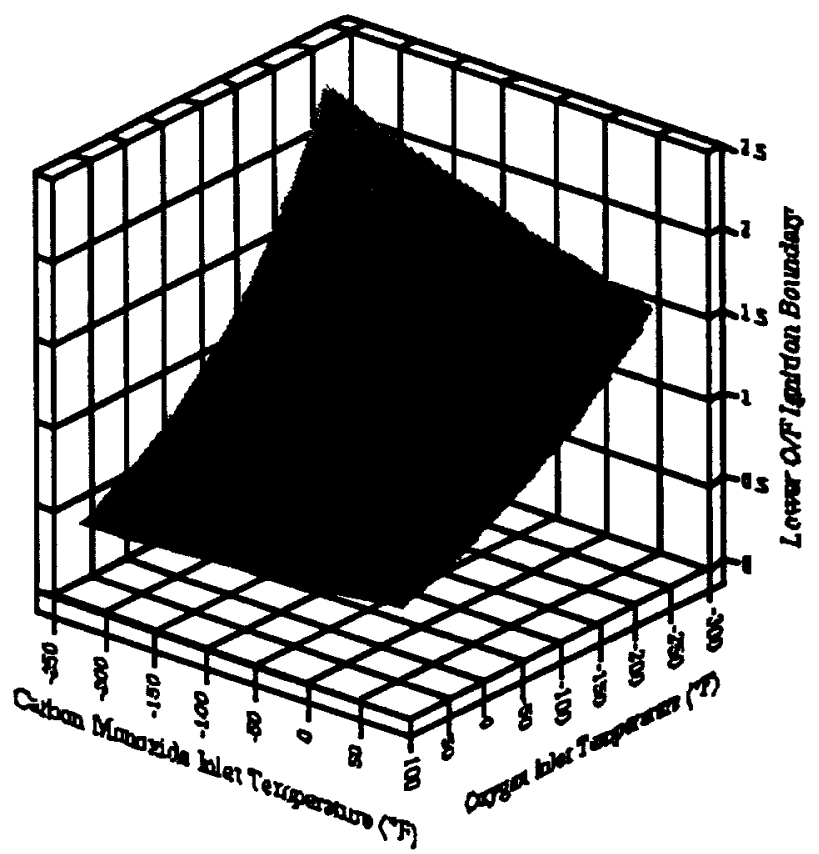

(b). - Response surface model.

Figure 5. Lower ignition boundary for carbon monoxide and oxygen.

dependent on carbon monoxide temperature squared.

Table II shows the ignition boundaries 
calculated from the analytical models at the experimental temperature conditions, and figure 7 combines the models for the lower and upper

Table II. Ignition Boundaries from Analytical Model.

\begin{tabular}{|c|c|c|c|c|c|}
\hline \multicolumn{3}{|c|}{ Lower Boundary } & \multicolumn{3}{|c|}{ Upper Boundary } \\
\hline $\begin{array}{l}\text { Ox. } \\
\left({ }^{\circ} \mathrm{F}\right)\end{array}$ & $\begin{array}{c}\mathrm{CO} \\
\left({ }^{\circ} \mathrm{F}\right)\end{array}$ & $\mathrm{O} / \mathrm{F}$ & $\begin{array}{l}\text { Ox. } \\
\left({ }^{\circ} F\right)\end{array}$ & $\begin{array}{l}\mathrm{CO} \\
\left({ }^{\circ} \mathrm{F}\right)\end{array}$ & $\mathrm{O} / \mathrm{F}$ \\
\hline-253 & -219 & 2.13 & -253 & -219 & 2.73 \\
\hline-251 & -138 & 1.93 & -260 & 2.8 & 1.16 \\
\hline-253 & -51 & 1.77 & -257 & 61 & 0.798 \\
\hline-258 & -8 & 1.72 & -93 & -163 & 2.99 \\
\hline-247 & 44 & 1.57 & -51 & -162 & 2.95 \\
\hline-173 & 63 & 1.21 & -173 & 63 & 1.45 \\
\hline-50 & 37 & 0.803 & -50 & 37 & 1.95 \\
\hline-24 & -207 & 0.656 & 51 & -214 & 2.73 \\
\hline-9 & -241 & 0.596 & 75 & 74 & 1.41 \\
\hline-1 & -52 & 0.642 & & & \\
\hline 41 & -55 & 0.541 & & & \\
\hline 75 & 74 & 0.546 & & & \\
\hline
\end{tabular}

boundaries onto one graph. The gray shaded area is the lower boundary, and the results at the two coldest temperatures are shown in solid white. The upper boundary surface is clear so that the entire mixture ratio range can be seen. At any temperature and mixture ratio combination within the region in the figure, oxygen and carbon monoxide should ignite and sustain combustion in the hardware tested.

Experimental data from previous tests (ref. 5) were also compared to the model generated from these tests. For this data, the model conservatively predicts the ignition range, except for one point where oxygen temperature was $-170^{\circ} \mathrm{F}$ (carbon monoxide temperature was $54^{\circ} \mathrm{F}$ for all tests). At this point, the model predicts a lower ignition

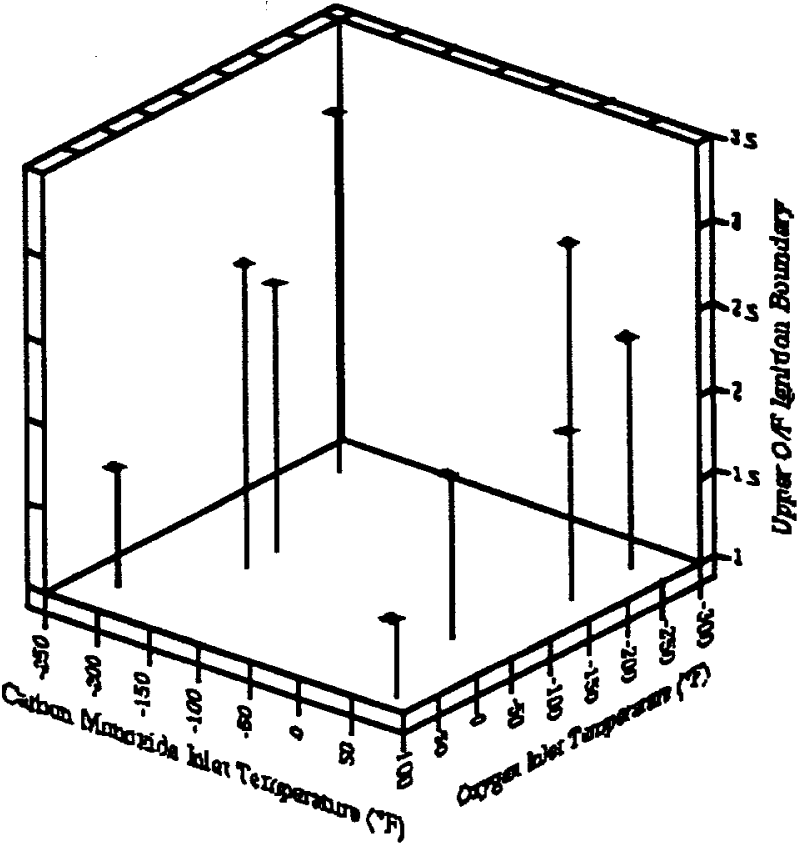

(a). - Experimental results.

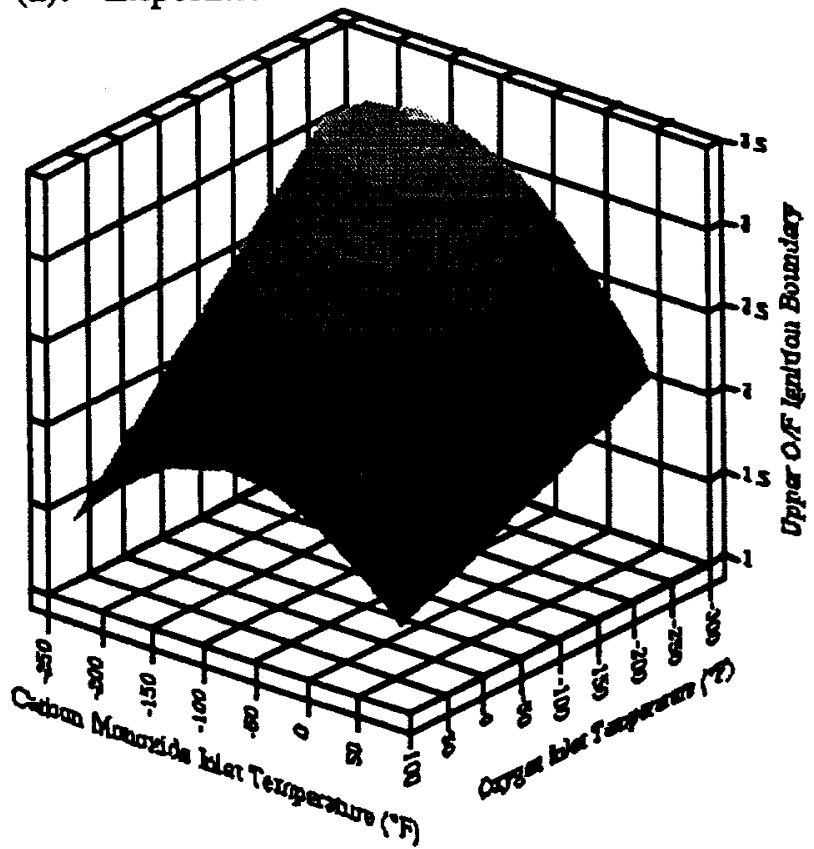

(b). - Response surface model.

Figure 6. Upper ignition boundary for carbon monoxide and oxygen.

boundary of 1.67 , while previously ignition was not achieved until a mixture ratio of 2.5 . In the current tests, however, with oxygen temperature at $-247^{\circ} \mathrm{F}$ and carbon monoxide 


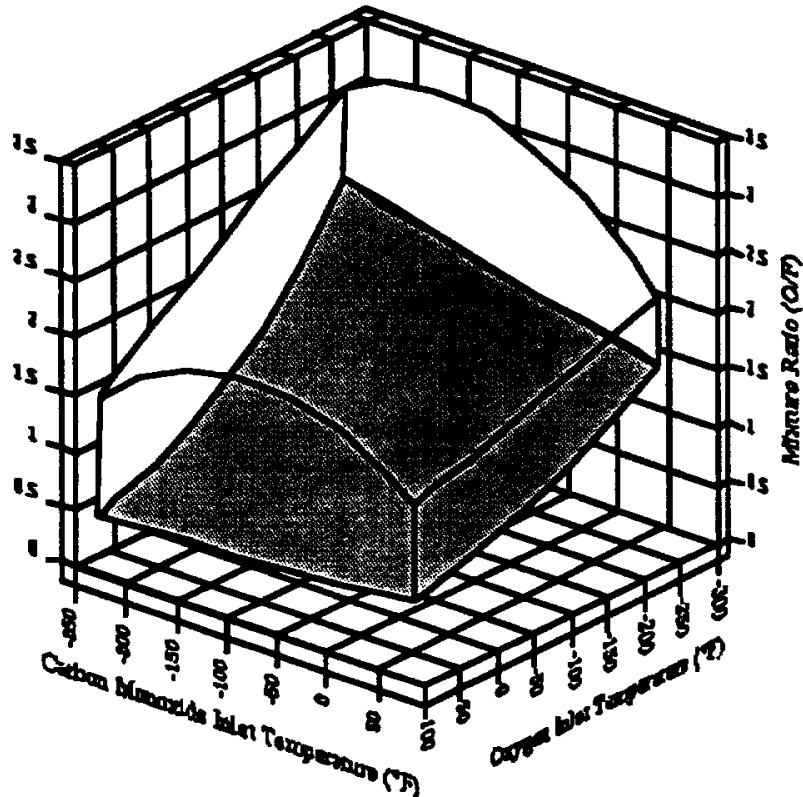

Figure 7. Analytical model of ignition range of carbon monoxide and oxygen based on experimental results.

temperature at $44^{\circ} \mathrm{F}$, ignition was achieved at mixture ratios as low as 1.29 . This discrepancy is an indication that repeatability may be an issue at some temperature conditions.

The analytical model would be most useful if ignition was guaranteed at any point within the indicated range. However, the model is only a representation of the mean of the data. When comparing the analytical model to the experimental data, it is clear that at some conditions mixture ratios calculated from the model lie outside of the range determined experimentally. In order to determine a model that could be used to select a condition more certain to result in ignition, 95 percent confidence intervals were calculated for each boundary. In this manner, the lower ignition boundary was increased until it represented a surface above which ignition was guaranteed to occur 95 percent of the time. Similarly, the upper boundary was decreased until it represented a surface below which ignition was guaranteed to occur 95 percent of the time. If at any condition the lower boundary became higher than the upper boundary, then ignition was considered suspect. Figure 8a shows the

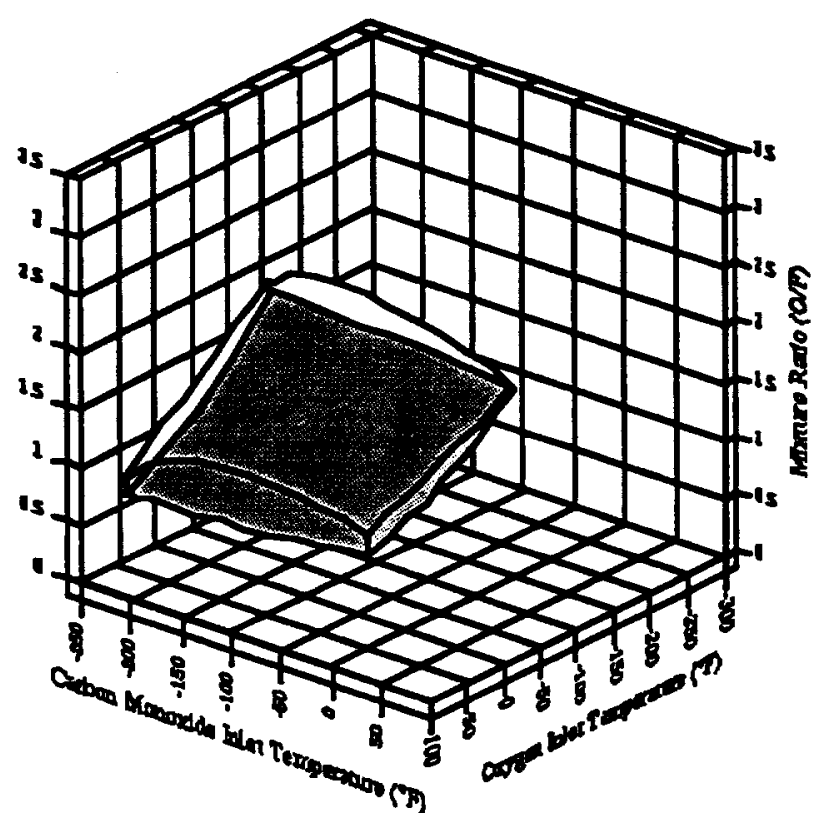

(a). - Ignition range at $90.25 \%$ confidence.

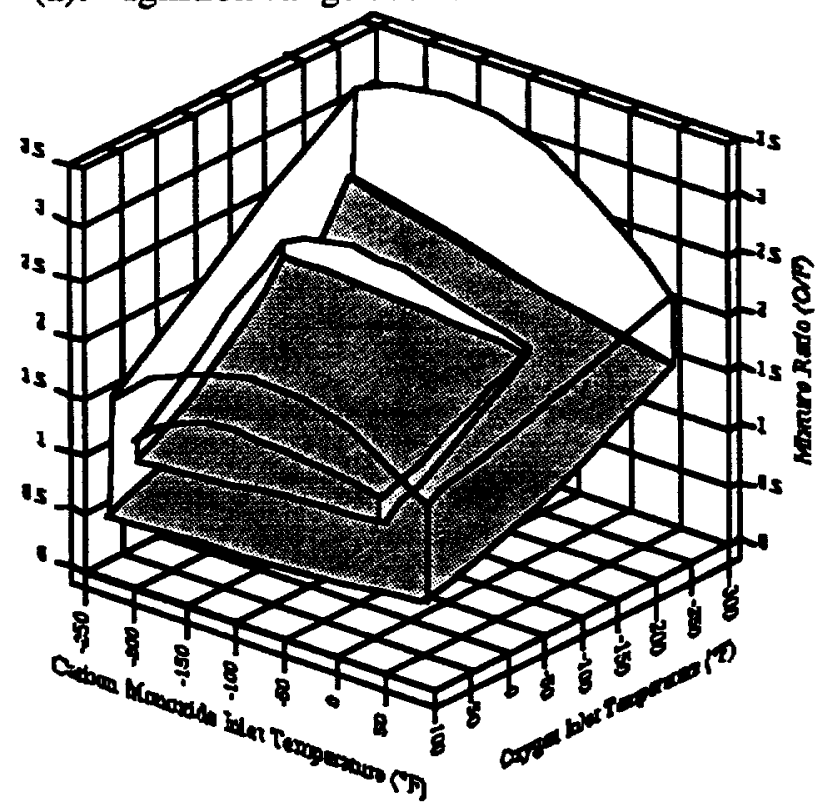

(b). - Original range compared to $90 \%$ confidence range.

Figure 8. Analytical models of ignition range of carbon monoxide and oxygen.

ignition range that provides 90.25 percent confidence of ignition (.95 confidence on lower boundary times .95 confidence on upper boundary). Figure $8 b$ compares the new ignition range to the original. 
It is clear from the figure that even with a relatively low confidence of 90 percent, the range of ignition conditions is small. While it is possible that additional experiments would allow a greater confidence in the model and therefore a larger ignition range at 90 percent confidence, it is uncertain whether the ignition of carbon monoxide and oxygen in this hardware, at any mixture ratio, can be proven at the high level of confidence required for autonomous planetary missions. The results of these tests and analysis indicate that an oxygen/carbon monoxide spark torch igniter may not be the best selection for a Mars mission.

\section{Simulated Small Rocket Engine Tests}

The results of the ignition tests indicate that the ignition range with cold propellants is a fairly narrow range high above the preferred engine operating conditions. If an engine on Mars was required to operate at mixture ratios so far from optimum (0.55), its specific impulse would be reduced by 25 percent, most likely eliminating the oxygen and carbon monoxide propellant combination from consideration for a Mars mission.

Therefore, to investigate whether the ignition results translated into engine operation constraints, the igniter hardware was modified to simulate a small engine. For this set of tests, the cold oxygen and cold carbon monoxide were injected into the igniter chamber as before. However, a second igniter chamber, without the long exit tube, was inserted before the $\mathrm{O}_{2} / \mathrm{CO}$ chamber (figure 9). The spark plug was inserted in this first chamber, and a small flow rate of gaseous oxygen and hydrogen (4.0 $\mathrm{gm} / \mathrm{sec}(0.0089 \mathrm{lbm} / \mathrm{sec})$ and $0.59 \mathrm{gm} / \mathrm{sec}$ $(0.0013 \mathrm{lbm} / \mathrm{sec})$, respectively) was injected and ignited. The hot gases from this $\mathrm{O}_{2} / \mathrm{H}_{2}$ combustion flowed into the second chamber along with the cold oxygen and carbon monoxide. As with the previous ignition experiments where the hydrogen was turned off once the oxygen and carbon monoxide combustion was initiated, in these tests the oxygen/hydrogen combustion was turned off once it performed its job of lighting the oxygen and carbon monoxide in the second chamber. With this sequence, it was possible to determine if oxygen and carbon monoxide could be ignited with a standard oxygen/hydrogen igniter, and also if the oxygen and carbon monoxide combustion would be self-sustaining after the ignition source was removed.

No hydrogen was added to the carbon monoxide in these tests. The only hydrogen used was in the first chamber. Based on current engines that use spark igniters, total flow time of igniter gases is assumed to be approximately 13 seconds. This includes 10 seconds of pre-flow and 3 seconds to allow the engine to obtain full thrust. Therefore, an oxygen/hydrogen spark torch igniter such as the one used in these tests would require that only approximately $15.4 \mathrm{gm}(0.034 \mathrm{lbm})$ of gaseous hydrogen be brought from Earth.

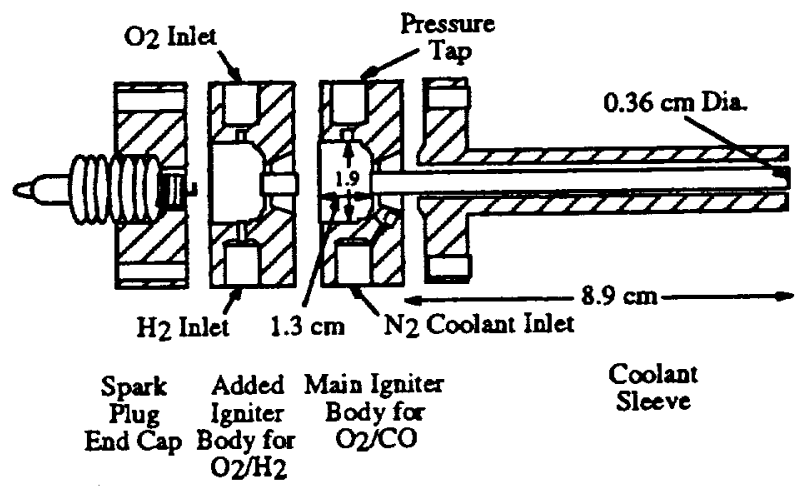

Figure 9. Simulated small rocket engine hardware.

Eleven tests were run in this hardware configuration, at mixture ratios of 2.4 (lower ignition boundary with cold propellants from ignition tests), 1.5, and 0.52. All 11 tests showed successful ignition and sustained combustion of the oxygen and carbon monoxide in the second chamber. After the pilot oxygen and hydrogen were shut off, the oxygen and carbon monoxide were allowed to burn for an additional 1.5 to 2.5 seconds to verify that steady state combustion had been achieved. Eight of the 11 tests were performed at a target mixture ratio of 0.55 ; actual mixture ratio obtained was approximately 0.52 . 
Oxygen temperatures ranged between -69 and $-238^{\circ} \mathrm{F}\left(-197^{\circ} \mathrm{F}\right.$ mean) and carbon monoxide temperatures ranged between -152 and $-229^{\circ} \mathrm{F}$ ( $-193^{\circ} \mathrm{F}$ mean). The consistent ignition and combustion in this test series indicates that cold oxygen and carbon monoxide can be successfully combusted in a rocket engine at mixture ratios at or near the optimum value of 0.55 .

\section{Conclusions}

The mixture ratio boundaries for oxygen and carbon monoxide were determined as a function of propellant temperature in a spark torch igniter that could be used in a 2200 $N$ (500 lbf) Mars sample return engine. The ignition range was between 0.50 and 1.44 with both propellants at room temperature; it was between 2.4 and 3.1 with both propellants chilled to near-liquid temperatures. Statistical analysis of the results showed that the lower mixture ratio boundary was more strongly dependent on the oxygen temperature than on the carbon monoxide temperature or the interaction between the oxygen and the carbon monoxide temperatures. The upper mixture ratio boundary was dependent on both oxygen and carbon monoxide temperatures, with a significant quadratic term for carbon monoxide temperature.

The results of the spark torch igniter tests and analytical models indicate that using oxygen and carbon monoxide as its own ignition source may not be the best design for a remote engine operating on Mars. Another common ignition source, however, should be able to ignite the main engine at the optimum mixture ratio of 0.55 . Tests were performed in a simulated small rocket engine, with oxygen/hydrogen combustion gases used as the ignition source for the oxygen and carbon monoxide. In these experiments, the oxygen and carbon monoxide was successfully ignited in 8 of 8 tests at a mixture ratio of 0.52 . In addition, the oxygen and carbon monoxide maintained steady combustion after the oxygen and hydrogen ignition source was removed. This steady-state combustion lasted until the oxygen and carbon monoxide were shut off, which varied from 1.5 to 2.5 seconds. This verifies that the oxygen and carbon monoxide rocket engine should continue to be included in mission plans for return propulsion from Mars.

\section{References}

1. Stancati, M.L., Jacobs, M.K., Cole, K.J., and Collins, J.T., "In Situ Propellant Production: Alternatives for Mars Exploration," NASA CR 187192, October, 1991.

2. French, J.R., "Rocket Propellants from Martian Resources," Journal of the British Interplanetary Society, Vol. 42, pp. 167-170, 1989.

3. Zubrin, R.M., Baker, D.A., and Gwynne, O., "Mars Direct: A Coherent Architecture for the Space Exploration Initiative," AIAA 91-2333, June, 1991.

4. Linne, D.L., and Meyer, M.L., "A compilation of Lunar and Mars Exploration Strategies Utilizing Indigenous Propellants," NASA TM 105262, January, 1992.

5. Linne, D.L., Roncace, J., and Groth, M.F., "Mars In Situ Propellants: Carbon Monoxide and Oxygen Ignition Experiments," NASA TM 103202, AIAA-90-1894, June, 1990.

6. Linne, D.L., "Carbon Monoxide and Oxygen Combustion Experiments: A Demonstration of Mars In Situ Propellants," NASA TM 104473, AIAA-91-2443, June, 1991.

7. Linne, D.L., "Performance and Heat Transfer Characteristics of a Carbon Monoxide/Oxygen Rocket Engine," NASA TM 105897, February, 1993.

8. Liou, L.C., "Laser Ignition in Liquid Rocket Engines," AIAA-94-2980, June, 1994. 
9. Urasek, D.C., and Calfo, F.D., "Space Chemical Propulsion Test Facilities at NASA Lewis Research Center," NASA TM 106050, April, 1993.

10. User's Manual, Computer Program $\mathrm{RS} / 1$, version 4.3, BBN Software Products, 1991. 


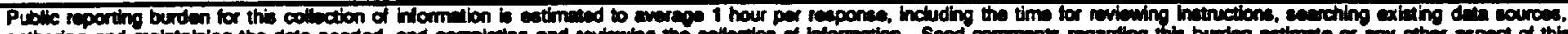
gewhering and maln

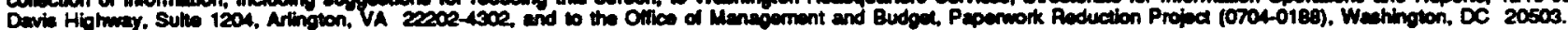

\begin{tabular}{|l|l|l}
\hline 1. AGENCY USE ONLY (Leave blank) & $\begin{array}{c}\text { 2 FEPCFT DATE } \\
\text { June } 1996\end{array}$ & $\begin{array}{r}\text { REPCRT TYPE ATD DATES COVERED } \\
\text { Technical Memorandum }\end{array}$
\end{tabular}

\section{TILE AND SUBTILE}

Experimental Evaluation of the Ignition Process of Carbon Monoxide and Oxygen in a Rocket Engine

6. AUTHOR(S)

Diane L. Linne

7. PERFORING ORGANZATION NAME(S) AND ADDAESS(ES)

National Aeronautics and Space Administration

Lewis Research Center

Cleveland, Ohio 44135-3191

9. SPONSORINGMONTORING AGENCY MANE(S) AND ADDPESS(ES)

National Aeronautics and Space Administration

Washington, D.C. 20546-0001
5. FUADING Numigers

WU-889-32-73

8. Perfogimg opganization REPOFT NUMBER

E-10334

10. SPONSORANGMONITORING AGENCY REPORT NUMBER

NASA TM-107267

AIAA-96-2943

11. SUPPLEMENTARY NOTES

Prepared for the 32nd Joint Propulsion Conference cosponsored by AIAA, ASME, SAE, and ASEE, Lake Buena Vista, Florida, July 1-3, 1996. Responsible person, Diane L. Linne, organization code 5310, (216) 977-7512.

12a. DISTRIBUTIONAVALABILTY STATEIENT 12b. DISTRIBUTION CODE

Unclassified - Unlimited

Subject Categories 20 and 28

This publication is available from the NASA Center for AeroSpace Information, (301) 621-0390.

13. ABSTRACT (Maximum 200 worda)

Carbon monoxide and oxygen ignition boundaries were determined in a spark torch igniter as a function of propellant inlet temperatures. The oxygen temperature was varied from ambient to $-258^{\circ} \mathrm{F}$, and the carbon monoxide temperature was varied from ambient to $-241^{\circ} \mathrm{F}$. With the oxygen and carbon monoxide at $-253^{\circ} \mathrm{F}$ and $-219^{\circ} \mathrm{F}$, respectively, they successfully ignited between mixture ratios of 2.42 and 3.10. Analysis of the results indicated that the lower ignition boundary was more sensitive to oxygen temperature than to carbon monoxide temperature. Another series of tests was performed in a small simulated rocket engine with oxygen at $-197^{\circ} \mathrm{F}$ and carbon monoxide at $-193^{\circ} \mathrm{F}$. An oxygen/hydrogen flame was used to initiate combustion of the oxygen and carbon monoxide. Tests performed at the optimum operating mixture ratio of 0.55 obtained steady-state combustion in every test.

14. SUBJECT TERMS

Carbon monoxide; Ignition; Combustion; Mars; Extraterrestrial resources 15. NUMBER OF PAGES 13

\begin{tabular}{l|c|c|c|}
$\begin{array}{l}\text { 17. SECURTY CLASSIFICATION } \\
\text { OF REPORT } \\
\text { Unclassified }\end{array}$ & $\begin{array}{c}\text { 18. SECURTY CLASSIFICATION } \\
\text { OF THIS PAGE } \\
\text { Unclassified }\end{array}$ & $\begin{array}{c}\text { 19. SECURTY CLASSIFICATION } \\
\text { OF ABSTRACT } \\
\text { Unclassified }\end{array}$
\end{tabular}




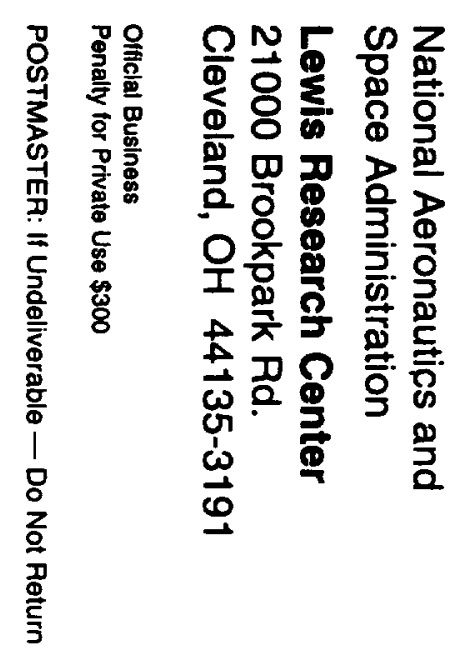

